Provided for non-commercial research and education use. Not for reproduction, distribution or commercial use.

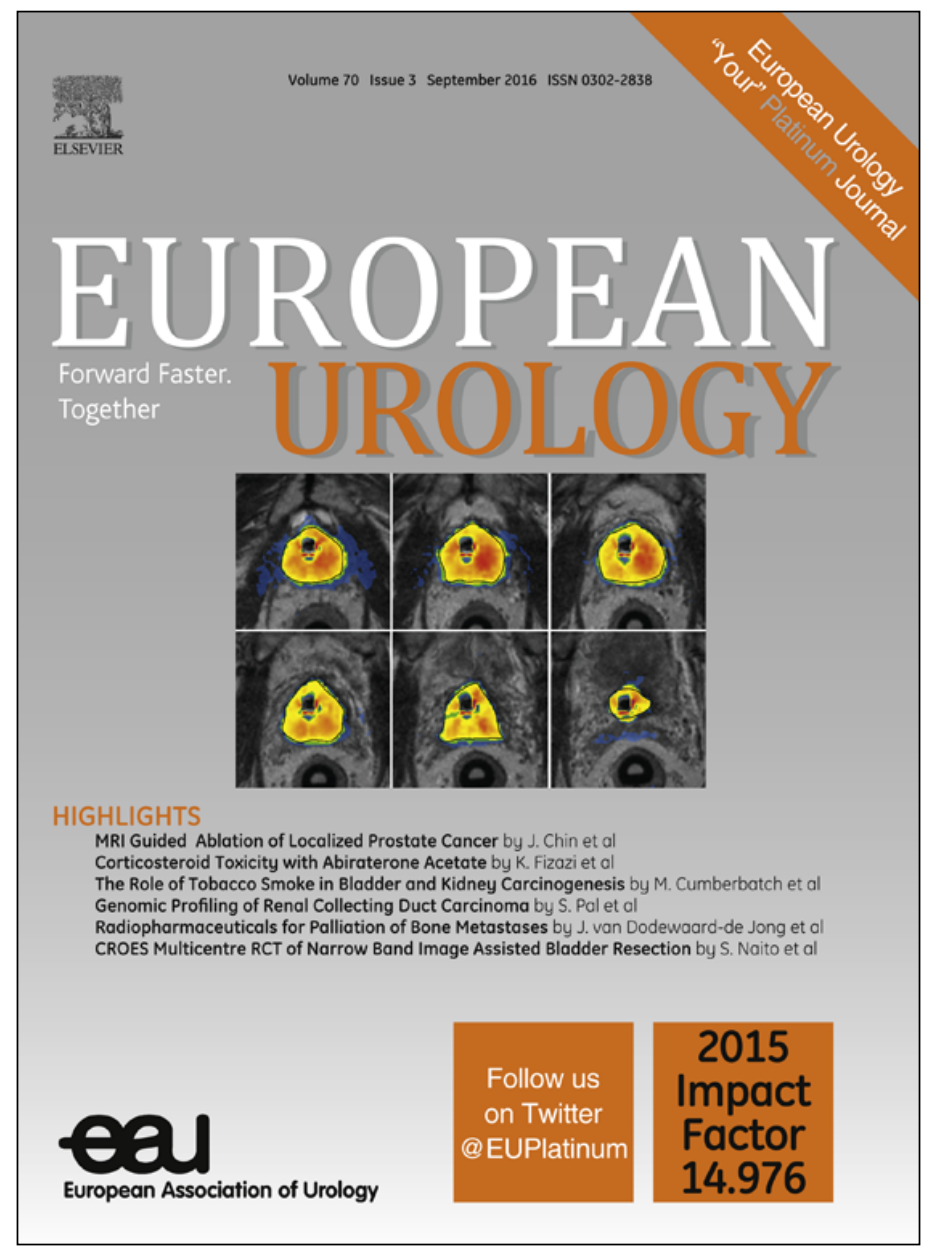

This article appeared in a journal published by Elsevier. The attached copy is furnished to the author for internal non-commercial research and education use, including for instruction at the author's institution and sharing with colleagues.

Other uses, including reproduction and distribution, or selling or licensing copies, or posting to personal, institutional or third party websites are prohibited.

In most cases authors are permitted to post their version of the article (e.g. in Word or Tex form) to their personal website or institutional repository. Authors requiring further information regarding Elsevier's archiving and manuscript policies are encouraged to visit:

http://www.elsevier.com/authorsrights 


\title{
Docetaxel Activity in the Era of Life-prolonging Hormonal Therapies for Metastatic Castration-resistant Prostate Cancer
}

\author{
Edoardo Francini ${ }^{a, b, *}$, Christopher J. Sweeney ${ }^{b}$

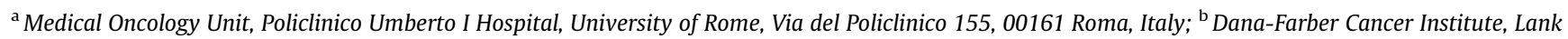 \\ Center for Genitourinary Oncology, 450 Brookline Avenue, Boston, MA 02215, USA
}

\section{Article info}

Article history:

Accepted May 2, 2016

\section{Associate Editor:}

James Catto

\section{Keywords:}

mCRPC

Docetaxel

Abiraterone

Activity

\begin{abstract}
For $>6 \mathrm{yr}$, docetaxel with prednisone was the only treatment with survival benefits for metastatic castration-resistant prostate cancer (mCRPC). More recently, in clinical practice, abiraterone acetate has been commonly administered prior to docetaxel for the treatment of mCRPC. Our study aimed to review the activity of docetaxel after prior abiraterone. To this end, we analyzed all retrospective reports in the literature describing the overall survival (OS) of mCRPC patients treated with docetaxel after previous abiraterone. The mean OS observed was $12.7 \mathrm{mo}$, which suggested a significant decrement compared with the 19.2 mo seen in the updated analysis of the TAX 327 study; however, the data are quite similar to the OS of $13.6 \mathrm{mo}$ (95\% confidence interval, 12.1$15.1 \mathrm{mo}$ ) described in a retrospective single-institution study of 357 men with mCRPC treated with docetaxel with no prior abiraterone mostly in routine practice (86.3\%). Because the characteristics of patients recruited in phase 3 trials tend to differ from the real-world setting, we deemed this data set a relevant comparison. Consequently, despite the limitations of retrospective cross-study comparisons, the data suggest that docetaxel retains activity when used as second-line therapy after abiraterone for MCRPC patients.

Patient summary: We reviewed the activity of docetaxel after prior use of abiraterone and considered the results in the light of the outcomes of docetaxel used as firstline therapy for metastatic castration-resistant prostate cancer (mCRPC) patients in routine practice. We noted that docetaxel retains reasonable activity and is a useful agent for the treatment of mCRPC patients before or after abiraterone.

(c) 2016 European Association of Urology. Published by Elsevier B.V. All rights reserved.

* Corresponding author. Dana-Farber Cancer Institute, Lank Center for Genitourinary Oncology, 450 Brookline Avenue, Boston, MA 02215, USA.

E-mail address: edoardo_francini@dfci.harvard.edu (E. Francini).
\end{abstract}

For $>6 \mathrm{yr}$, docetaxel with prednisone was the only therapy proven to prolong overall survival (OS) in patients with metastatic castration-resistant prostate cancer (mCRPC) [1] and became the standard of care; however, not all men were considered fit for chemotherapy and thus were not treated with docetaxel. Furthermore, in a retrospective singleinstitution study of 357 men with mCRPC treated with docetaxel from 2001 to 2011 mostly in routine practice (86.3\%), the median OS was 13.6 mo (95\% confidence interval [CI], 12.1-15.1 mo) compared with $19.2 \mathrm{mo}$ (95\% CI, 17.5-21.3 mo) observed in the updated analysis of the TAX 327 study [2]. The authors concluded that survival of patients with mCRPC treated with docetaxel in clinical practice is shorter and is associated with more toxicity than that of men included in trials [3].

The recent advent of two novel androgen receptor (AR) targeted therapies-abiraterone acetate, a selective irreversible inhibitor of P-450c17, and enzalutamide, a potent 
AR antagonist and signaling inhibitor-changed the therapeutic landscape of mCRPC. Given their improved survival benefit, lower adverse event profile, oral administration, and consequently greater proportions of patients who are candidates for these therapies, they became the more common first-line treatment. Analyses of prescriptions showed that in 2010, $91 \%$ of US men with MCRPC fit for available therapy received docetaxel as first-line treatment, whereas in 2013 , this number had decreased to only $15 \%$, as $67 \%$ of patients were treated with abiraterone as first-line MCRPC therapy [4].

At this juncture, it was questioned whether the efficacy of docetaxel was affected by prior abiraterone. To this end, several retrospective reports identified by a literature search (Appendix) investigated the clinical outcomes of mCRPC patients treated with docetaxel after previous abiraterone [5-9]. In aggregate, results showed that prostate-specific antigen (PSA) decline $\geq 50 \%$ ranged from $13 \%$ to $48 \%$, and OS ranged from 12.4 to $14.4 \mathrm{mo}$ (Table 1 ). Interestingly, some of these papers noted no response to docetaxel in patients who showed primary resistance to abiraterone [6,7]. This led to speculation about the possibility of cross-resistance between abiraterone and docetaxel. Conversely, a report by Schweizer et al, who compared the efficacy of docetaxel in patients who did $(n=24)$ or did not $(n=95)$ receive prior abiraterone, described responses to docetaxel in the group of patients who had no response to prior abiraterone [7]. These results were also supported by a Canadian multicenter retrospective study that retrospectively analyzed 86 patients treated with docetaxel after failure of abiraterone. A PSA decline of $\geq 50 \%$ was observed in 30 of 86 patients ( $35 \%$; $95 \% \mathrm{Cl}, 26-45 \%$ ), and the median OS was 11.66 mo (95\% Cl, 9.45-13.88 mo); however, no statistically significant differences in PSA response or OS were observed for patients with no PSA decline, with $<50 \%$ decline, and with $\geq 50 \%$ decline on abiraterone [9].

The conflicting findings of these retrospective reports highlight the need for prospective multicenter evaluations of therapies rather than drawing conclusions from singleinstitution reports based on end points of unclear significance such as PSA decline. In this respect, a post hoc analysis of COU-AA-302 revealed that $27 \%$ of 100 patients who had docetaxel after abiraterone and at least one PSA measurement on therapy had a confirmed decline of $\geq 50 \%$ [10]. Nonetheless, there was consistency of the median OS for all of these studies of men treated with docetaxel after abiraterone, and the mean OS value was $12.7 \mathrm{mo}$. At first look, these data would suggest a significant decrement of activity of docetaxel used after abiraterone compared with docetaxel used with no prior abiraterone, as reported in the final survival analysis of TAX 327 (OS was $19.2 \mathrm{mo}$ ) [2]. However, if compared with the OS achieved with firstline docetaxel in routine practice [3], the OS of docetaxel after abiraterone reported in similar institutional retrospective reviews appears similar (13.6 vs $12.7 \mathrm{mo}$ ). The discrepancy between the results from clinical practice and the OS from the phase 3 clinical trial setting is probably due to the restrictiveness of the eligibility criteria. At baseline, patients in TAX 327 had better prognostic features than those in the series by Templeton et al. [3] (Table 1): poor performance score, $13 \%$ versus $29 \%$; Gleason score $8-10$, $31 \%$ versus 58\%; and median PSA, 114 versus $164 \mathrm{ng} / \mathrm{ml}$. As such, it should be noted that the characteristics of the trial population would portend a better prognosis than in the

Table 1 - Patient characteristics and results

\begin{tabular}{|c|c|c|c|c|c|c|c|}
\hline Variable & TAX 327 [2] & $\begin{array}{l}\text { SWOG } \\
9916[1]\end{array}$ & $\begin{array}{l}\text { Templeton } \\
\text { et al. [3] }\end{array}$ & $\begin{array}{c}\text { Mezynski } \\
\text { et al. [5] }\end{array}$ & $\begin{array}{c}\text { Azad } \\
\text { et al. [8] }\end{array}$ & $\begin{array}{l}\text { Aggarwal } \\
\text { et al. [9] }\end{array}$ & Ueda et al. [6] \\
\hline Type of study & $\begin{array}{l}\text { Phase } 3 \\
\text { trial }\end{array}$ & $\begin{array}{l}\text { Phase } 3 \\
\text { trial }\end{array}$ & $\begin{array}{l}\text { Hospital } \\
\text { registry }\end{array}$ & $\begin{array}{l}\text { Hospital } \\
\text { registry }\end{array}$ & $\begin{array}{l}\text { Hospital } \\
\text { registry }\end{array}$ & $\begin{array}{l}\text { Hospital } \\
\text { registry }\end{array}$ & $\begin{array}{l}\text { Hospital } \\
\text { registry }\end{array}$ \\
\hline After abiraterone & No & No & No & Yes & Yes & Yes & Yes \\
\hline Patients, $n$ & 335 & 386 & 314 & 35 & 86 & 23 & 15 \\
\hline Age, yr, median & 68 & 70 & 71 & 71 & 71 & 67 & 71 \\
\hline \multicolumn{8}{|l|}{ Gleason score, $n(\%)$} \\
\hline$\leq 6-7$ & $141(42)$ & - & $105(43)$ & $14(40)$ & $27(31)$ & $6(26)$ & $3(20)$ \\
\hline $8-10$ & $104(31)$ & - & $142(58)$ & $18(51)$ & $46(53)$ & $17(74)$ & $11(73)$ \\
\hline \multicolumn{8}{|l|}{ PS, \% } \\
\hline Poor & $13^{*}$ & $10^{\sim}$ & $29^{\#}$ & $9^{\#}$ & $34^{\#}$ & - & $7^{\#}$ \\
\hline Median PSA, ng/mL & 114 & 84 & 164 & 232 & 184 & 260 & 67 \\
\hline \multicolumn{8}{|l|}{ Sites of disease, $n(\%)$} \\
\hline Bone & $301(90)$ & $324(84)$ & $273(87)$ & $33(94)$ & $81(94)$ & $21(91)$ & $12(80)$ \\
\hline Lymph nodes & - & $93(24)$ & $159(51)$ & $10(31)$ & $46(53)$ & - & $6(40)$ \\
\hline Visceral & $74(22)$ & $69(18)$ & $60(19)$ & $4(11)$ & $17(20)$ & $2(9)$ & $3(8)$ \\
\hline \multicolumn{8}{|l|}{ OS, mo } \\
\hline Median & 19.2 & 17.5 & 13.6 & 12.5 & 11.66 & 12.4 & 14.4 \\
\hline $95 \% \mathrm{CI}$ & $17.5-21.3$ & - & $12.1-15.1$ & $10.6-19.4$ & $9.4-13.9$ & $8.2-19.6$ & $6.3-22.4$ \\
\hline \multicolumn{8}{|l|}{ PSA decline $\geq 50 \%, \%$} \\
\hline Rate & 45 & 50 & 45 & 26 & 35 & 48 & 13 \\
\hline $95 \% \mathrm{CI}$ & $40-51$ & - & $39-51$ & $13-43$ & $26-45$ & - & - \\
\hline $\begin{array}{l}\text { CI = confidence interva } \\
\text { Karnofsky PS } \leq 70 . \\
\sim \text { SWOG PS } \geq 2 . \\
\text { " Eastern Cooperative }\end{array}$ & 5y Group PS > & perform & $\mathrm{Is} ; \mathrm{PSA}=\mathrm{pr}$ & pecific an & & & \\
\hline
\end{tabular}


real-world setting when one considers the components of prognostic nomograms [11]. This holds particularly true for prostate cancer patients who are often elderly, have comorbidities, and may be more vulnerable to the adverse events of any given therapy, particularly a cytotoxic one such as docetaxel. Consequently, even though in phase 3 trials the OS benefit provides evidence of the clinical activity of docetaxel, we cannot assume the general population will have the same survival rates. The more appropriate comparison might be the aggregate OS data gathered from the studies on docetaxel as second-line therapy after abiraterone beyond a clinical trial setting (12.7 mo) versus the 13.6 mo reported by Templeton et al. [3]. When considered in this light, it would appear that docetaxel after abiraterone maintains a degree of activity similar to that when given without prior abiraterone in routine practice. Unfortunately, the only comparisons that can be made are cross-study comparisons of PSA decline, time to progression, and OS rates from registry data, as randomized controlled trials are not available. Because docetaxel after abiraterone is used at a later and potentially more aggressive stage, one could postulate that it would be less effective. Alternatively, it is known that non-ARdependent disease is sensitive to docetaxel in CRPC as well as in lung, breast, and gastric cancer.

In conclusion, given the limitations of retrospective crossstudy comparisons, the totality of the data would suggest that docetaxel used as second-line therapy after abiraterone retains reasonable activity and is a useful agent for the treatment of MCRPC patients, before or after abiraterone.

Author contributions: Edoardo Francini had full access to all the data in the study and takes responsibility for the integrity of the data and the accuracy of the data analysis.

Study concept and design: Francini, Sweeney.

Acquisition of data: Francini.

Analysis and interpretation of data: Francini, Sweeney.

Drafting of the manuscript: Francini.

Critical revision of the manuscript for important intellectual content: Sweeney.

Statistical analysis: None.

Obtaining funding: None.

Administrative, technical, or material support: None.

Supervision: Sweeney.

Other (specify): None.

Financial disclosures: Edoardo Francini certifies that all conflicts of interest, including specific financial interests and relationships and affiliations relevant to the subject matter or materials discussed in the manuscript (eg, employment/affiliation, grants or funding, consultancies, honoraria, stock ownership or options, expert testimony, royalties, or patents filed, received, or pending), are the following: Christopher J. Sweeney is a consultant with compensation from Sanofi, Janssen Pharmaceutical Companies, BIND Therapeutics Inc., Astellas Pharma, and Bayer.

Funding/Support and role of the sponsor: None.

\section{Appendix A. Appendix-Search terms}

The PubMed/Medline, Embase, LILACS, Cochrane Library, and American Society of Clinical Oncology (ASCO) and European Society of Medical Oncology (ESMO) abstracts databases were searched for relevant articles using the following terms: docetaxel after abiraterone, abiraterone followed by docetaxel, docetaxel with prior abiraterone, abiraterone before docetaxel, abiraterone and subsequent docetaxel.

\section{References}

[1] Petrylak DP, Tangen CM, Hussain MHA, et al. Docetaxel and estramustine compared with mitoxantrone and prednisone for advanced refractory prostate cancer. N Engl J Med 2004;351:1513-20.

[2] Berthold DR, Pond GR, Soban F, de Wit R, Eisenberger M, Tannock IF. Docetaxel plus prednisone or mitoxantrone plus prednisone for advanced prostate cancer: updated survival in the TAX 327 study. J Clin Oncol 2008;26(2):242-5.

[3] Templeton AJ, Vera-Badillo FE, Wang L, et al. Translating clinical trials to clinical practice: outcomes of men with metastatic castration resistant prostate cancer treated with docetaxel and prednisone in and out of clinical trials. Ann Oncol 2013;24:2972-7.

[4] Flaig TW, Potluri RC, Ng Y, Todd MB, Mehra M. Treatment evolution for metastatic castration-resistant prostate cancer with recent introduction of novel agents: retrospective analysis of real-world. Cancer Med 2016;5:182-91.

[5] Mezinsky J, Pezaro C, Bianchini D, et al. Antitumour activity of docetaxel following treatment with the CYP17A1 inhibitor abiraterone: clinical evidence for cross-resistance? Ann Oncol 2012;23: 2943-7.

[6] Ueda Y, Matsubara N, Takizawa I, et al. A multicenter retrospective analysis of sequential treatment of abiraterone acetate followed by docetaxel in Japanese patients with metastatic castration-resistant prostate cancer. Jpn J Clin Oncol 2015;45:774-9.

[7] Schweizer MT, Zhou XC, Wang H, et al. The influence of prior abiraterone treatment on the clinical activity of docetaxel in men with metastatic castration-resistant prostate cancer. Eur Urol 2014;66:646-52.

[8] Azad AA, Leibowitz-Amit R, Eigl BJ, et al. A retrospective, canadian multi-center study examining the impact of prior response to abiraterone acetate on efficacy of docetaxel in metastatic castration-resistant prostate cancer. Prostate 2014;74:1544-50.

[9] Aggarwal R, Harris A, Formaker C, et al. Response to subsequent docetaxel in a patient cohort with metastatic-castration prostate cancer after abiraterone acetate treatment. Clin Genitourin Cancer 2014;12:e167-72.

[10] Flaig TW, Smith MR, Saad F, et al. Treatment patterns after abiraterone acetate in patients (pts) with metastatic castration-resistant prostate cancer ( $\mathrm{MCRPC}$ ): post hoc analysis of COU-AA-302 [abstract 168]Presented at: 2016 Genitourinary Cancers Symposium; January 7-9; San Francisco, CA; 2016.

[11] Halabi S, Lin CY, Kelly WK, et al. Updated prognostic model for predicting overall survival in first-line chemotherapy for patients with metastatic castration-resistant prostate cancer. J Clin Oncol 2014;32:671-7. 